\title{
The length of stay in the post-anaesthesia care unit correlates with pain intensity, nausea and vomiting on arrival
}

Michael T Ganter', Stephan Blumenthal ${ }^{2}$, Seraina Dübendorfer ${ }^{2}$, Simone Brunnschweiler², Tim Hofer², Richard Klaghofer ${ }^{3}$, Andreas Zollinger ${ }^{2}$ and Christoph $\mathrm{K} \mathrm{Hofer}^{2^{*}}$

\begin{abstract}
Background: The benefit of the post-anaesthesia care unit (PACU) with respect to an early detection of postoperative complications is beyond dispute. From a patient perspective, prevention and optimal management of pain, nausea and vomiting (PONV) are also of utmost importance. The aims of the study were therefore to prospectively measure pain and PONV on arrival to the PACU and before discharge and to determine the relationship of pain and PONV to the length of stay in the PACU.
\end{abstract}

Methods: Postoperative pain was assessed over 30 months using a numeric rating scale on admittance to the PACU and before discharge; in addition, PONV was recorded. Statistical analysis was done considering gender, age, American Society of Anesthesiologists (ASA) classification, surgical speciality, anaesthesia technique, duration of anaesthesia, intensity of nursing and length of stay.

Results: Data of 12,179 patients were available for analysis. The average length of stay in the PACU was $5.7 \pm 5.9 \mathrm{~h}$, whereas regular PACU patients stayed for $3.2 \pm 1.9 \mathrm{~h}$ and more complex IMC patients stayed for $15.1 \pm 6.0 \mathrm{~h}$. On admittance, $27 \%$ of patients were in pain and the number decreased to $13 \%$ before discharge; $3 \%$ experienced PONV. Risk factors for increased pain determined by multivariate analysis were female gender; higher ASA classification; general, cardiac and orthopaedic surgery and prolonged case duration. In more complex IMC patients, pain scores were higher on arrival but dropped to similar levels before discharge compared to regular PACU patients. Female gender and postoperative pain were risk factors for postoperative vomiting. Pain and PONV on arrival correlated with length of stay in the PACU. Pain- or PONV-free patients stayed almost half of the time in the PACU compared to patients with severe pain or vomiting on arrival.

Conclusions: The majority of PACU patients had good pain control, both on admittance and before discharge, and the overall incidence of PONV was low. Managing patients in the PACU could achieve a significant reduction of pain and PONV. The level of pain and presence of PONV on admittance to the PACU correlate with and act as predictors for increased length of PACU stay.

Keywords: Post-anaesthesia care unit (PACU), Postoperative pain, Postoperative nausea, Postoperative vomiting, PONV

\footnotetext{
* Correspondence: christoph.hofer@triemli.stzh.ch

${ }^{2}$ Institute of Anaesthesiology and Intensive Care Medicine, Triemli City

Hospital Zurich, Birmensdorferstrasse 497, 8063 Zurich, Switzerland

Full list of author information is available at the end of the article
} 


\section{Background}

Today, post-anaesthesia care units (PACUs) are a standard and integral part of daily anaesthesia practice in most developed countries. Their main purpose is to safely recover patients from surgical and interventional procedures with concomitant anaesthesia. Through structured and tight clinical observation combined with continuous patient monitoring, discomfort and complications can be identified and treated early, thereby reducing adverse outcomes and increasing efficacy [1]. Several practice guidelines for post-anaesthesia care are available and have been recently updated, such as those from the European Board of Anaesthesiology and the American Society of Anesthesiologists $[2,3]$.

The benefit of a PACU service with respect to early detection of postoperative complications is beyond dispute. From a patient perspective, however, prevention and optimal management of pain, nausea and vomiting are of utmost importance as well. Therefore, the degree of pain, quantity of pain relief over time and the presence of postoperative nausea and vomiting (PONV) are being used as popular quality indicators for anaesthesia and postoperative care in PACU audits $[2,4]$.

The first aim of the present study was to prospectively measure pain and PONV at two defined time points: on arrival to our PACU and before discharge to the ward. As a quality management project, we wanted to specifically monitor these indicators and to compare our results to published reports. The second aim of the study was to determine if pain and PONV on arrival correlate with the length of stay in our PACU. It is important to early identify patients at risk for unplanned, prolonged PACU stay for optimal perioperative efficiency [5]. If the PACU becomes congested by these patients, the outflow of

Table 1 Patient characteristics and case-related data of 12,179 PACU patients

\begin{tabular}{|c|c|c|c|c|c|c|}
\hline & & \multicolumn{2}{|c|}{ Numbers, $n$ (\%) } & \multicolumn{3}{|c|}{ Length of stay, hours } \\
\hline & & & & All patients & Regular PACU & IMC \\
\hline \multirow[t]{2}{*}{ Gender } & Women & 5,866 & $(48)$ & $6.1 \pm 5.9$ & $3.4 \pm 2.1$ & $14.7 \pm 6.2^{*}$ \\
\hline & Men & 6,313 & $(52)$ & $5.4 \pm 5.8^{* *}$ & $2.9 \pm 1.8^{* *}$ & $15.6 \pm 5.7^{*, * *}$ \\
\hline \multirow[t]{3}{*}{ Age } & $<40$ years & 1,312 & $(11)$ & $4.4 \pm 4.8$ & $2.9 \pm 1.8$ & $14.4 \pm 6.7^{*}$ \\
\hline & $40-80$ years & 8,009 & $(66)$ & $5.7 \pm 6.0^{* *}$ & $3.1 \pm 2.0^{* *}$ & $15.8 \pm 5.7^{* * * *}$ \\
\hline & $>80$ years & 2,858 & $(24)$ & $6.4 \pm 6.1^{* *}$ & $3.3 \pm 2.1^{* *}$ & $14.0 \pm 6.4^{*}$ \\
\hline \multirow[t]{4}{*}{ ASA classification } & ASA I & 1,949 & $(16)$ & $3.7 \pm 3.9$ & $2.8 \pm 1.6$ & $14.3 \pm 6.5^{*}$ \\
\hline & ASA II & 5,480 & $(45)$ & $5.4 \pm 5.6^{* *}$ & $3.1 \pm 2.0^{* *}$ & $15.3 \pm 5.8^{* * * *}$ \\
\hline & ASA III & 4,628 & (38) & $6.9 \pm 6.5^{* *}$ & $3.3 \pm 2.2^{* *}$ & $15.1 \pm 6.1^{*}$ \\
\hline & ASA IV & 122 & $(1)$ & $9.8 \pm 8.4^{* *}$ & $4.4 \pm 3.3^{* *}$ & $15.7 \pm 8.3^{*}$ \\
\hline \multirow[t]{7}{*}{ Surgical specialities } & General surgery & 7,237 & $(59)$ & $6.4 \pm 6.3$ & $3.4 \pm 2.1$ & $14.6 \pm 6.3^{*}$ \\
\hline & Cardiac surgery & 667 & $(5)$ & $6.8 \pm 6.9$ & $2.8 \pm 1.6^{* *}$ & $17.3 \pm 4.1^{*, * *}$ \\
\hline & Orthopaedic surgery & 675 & (6) & $7.1 \pm 5.4^{* *}$ & $4.8 \pm 1.9^{* *}$ & $16.1 \pm 4.9^{* * * *}$ \\
\hline & Spine surgery & 603 & (6) & $6.4 \pm 5.8$ & $3.5 \pm 2.1$ & $15.1 \pm 4.3^{*}$ \\
\hline & Urology & 1,584 & $(13)$ & $5.0 \pm 4.6^{* *}$ & $2.7 \pm 1.6^{* *}$ & $16.9 \pm 4.9^{* * * *}$ \\
\hline & Ophthalmology & 1,267 & $(10)$ & $2.3 \pm 1.9^{* *}$ & $2.1 \pm 0.9^{* *}$ & $14.2 \pm 4.5^{* * * *}$ \\
\hline & ENT surgery & 146 & $(1)$ & $3.8 \pm 4.2^{* *}$ & $2.6 \pm 1.5^{* *}$ & $16.7 \pm 3.5^{*}$ \\
\hline \multirow[t]{5}{*}{ Anaesthetic techniques } & MAC & 436 & (3) & $4.7 \pm 5.7$ & $2.7 \pm 1.5^{* *}$ & $16.9 \pm 5.9^{*, * *}$ \\
\hline & Peripheral RA & 76 & $(1)$ & $5.8 \pm 6.9$ & $4.0 \pm 2.1$ & $12.2 \pm 5.7^{* * * *}$ \\
\hline & Central neuraxial RA & 1,048 & (9) & $4.1 \pm 4.3^{* *}$ & $3.0 \pm 1.8$ & $15.6 \pm 5.7^{*}$ \\
\hline & General anaesthesia & 8,979 & $(74)$ & $5.3 \pm 5.7$ & $3.0 \pm 1.9$ & $15.1 \pm 6.0^{*}$ \\
\hline & Combined anaesthesia & 1,640 & $(13)$ & $8.8 \pm 6.8^{* *}$ & $4.3 \pm 2.3^{* *}$ & $15.0 \pm 5.9^{*}$ \\
\hline \multirow[t]{3}{*}{ Duration of anaesthesia } & $<60 \min$ & 196 & $(4)$ & $5.0 \pm 6.1$ & $2.6 \pm 1.5$ & $16.2 \pm 6.7^{*}$ \\
\hline & $60-180 \mathrm{~min}$ & 7,888 & $(63)$ & $4.0 \pm 4.1^{* *}$ & $2.9 \pm 1.7$ & $14.1 \pm 6.6^{*}$ \\
\hline & $>180 \min$ & 4,095 & $(33)$ & $8.8 \pm 7.1^{* *}$ & $3.9 \pm 2.4^{* *}$ & $15.5 \pm 5.7^{*}$ \\
\hline Intensity of nursing care & Regular PACU/IMC & $9,603 / 2,576$ & $(78 / 22)$ & $5.7 \pm 5.9$ & $3.2 \pm 2.3$ & $15.1 \pm 6.0^{*}$ \\
\hline
\end{tabular}

ASA classification American Society of Anesthesiologists' classification, ENT ear-nose-throat, IMC intermediate care (more complex, intermediate care patients, NEMS >15), MAC monitored anaesthesia care, PACU post-anaesthesia care unit (regular post-anaesthesia care unit patients, NEMS $\leq 15), R A$ regional anaesthesia. ${ }^{*} p<0.05$ (comparison PACU-IMC), ${ }^{* *} p<0.05$ (age: comparison with age <40 years; ASA classification: comparison with ASA l; surgical specialities: comparison with general surgery; anaesthetic technique: comparison with general anaesthesia; duration of anaesthesia: comparison with duration $<60$ min). 
patients from the PACU to the ward is stopped and the unit cannot receive any further patients from the operating room (OR).

\section{Methods}

After approval from the local ethic committee (Kantonale Ethik Kommission, 8090 Zurich, Switzerland: KEK-StV-Nr. 47/12), which waived the requirement for informed consent, the anaesthesia quality management project was established. Data were prospectively collected in the PACU of the Triemli City Hospital Zurich, Switzerland during a time period of 30 months.

\section{Postoperative patient flow and care in our hospital}

Depending on patient- and procedure-related factors, patients are either being recovered from surgical and interventional procedures with concomitant anaesthesia in the PACU or are being sent directly to the ward (inpatients to the regular, surgical ward; outpatients to the ambulatory holding area). Except for the ICU, our PACU represents the only unit where continuous patient monitoring and a higher level of nursing care can be provided after anaesthesia. Our PACU, open 24/7, has ten beds with continuous full patient monitoring. The PACU staffing consists of a nurse to bed ratio of 1:3 on an average per day shift on a week day; the surgical ward has a ratio of 1:6 and no continuous patient monitoring available.

Patients are being admitted to the PACU when patient- or procedure-related factors require specific PACU care, i.e. co-morbidities, American Society of Anesthesiologists (ASA) classification $\geq 3$, prolonged anaesthesia and major surgery, general anaesthesia with neuromuscular blockade, starting and titrating opioid or local anaesthetic pain pumps or mandatory prolonged postoperative observation. Patients stayed overnight, if necessary.

\section{Baseline data and patient categories}

Patient characteristics (gender, age, ASA classification) and case-related data (surgical speciality, type and duration of anaesthesia, length of stay in the PACU) of all PACU patients were recorded. To measure nursing workload and complexity, NEMS (nine equivalents of nursing manpower use score [6]) was calculated for every patient. Thereby, patients were categorized into two groups: regular PACU patients (NEMS $\leq 15)$, and more complex intermediate care patients (IMC; NEMS >15).

\section{Postoperative pain, nausea and vomiting}

On admittance to the PACU and before discharge to the regular ward, patients were asked for pain, nausea and vomiting. Level of pain was assessed using the numeric rating scale (NRS, graded from zero to ten), and patients were asked to express the intensity of their actual pain score in numbers [7].

Pain management was done according to institutional standards using a multimodal approach [8,9]. Depending on the underlying and concomitant diseases, analgesia was done with paracetamol, non-steroidal anti-inflammatory

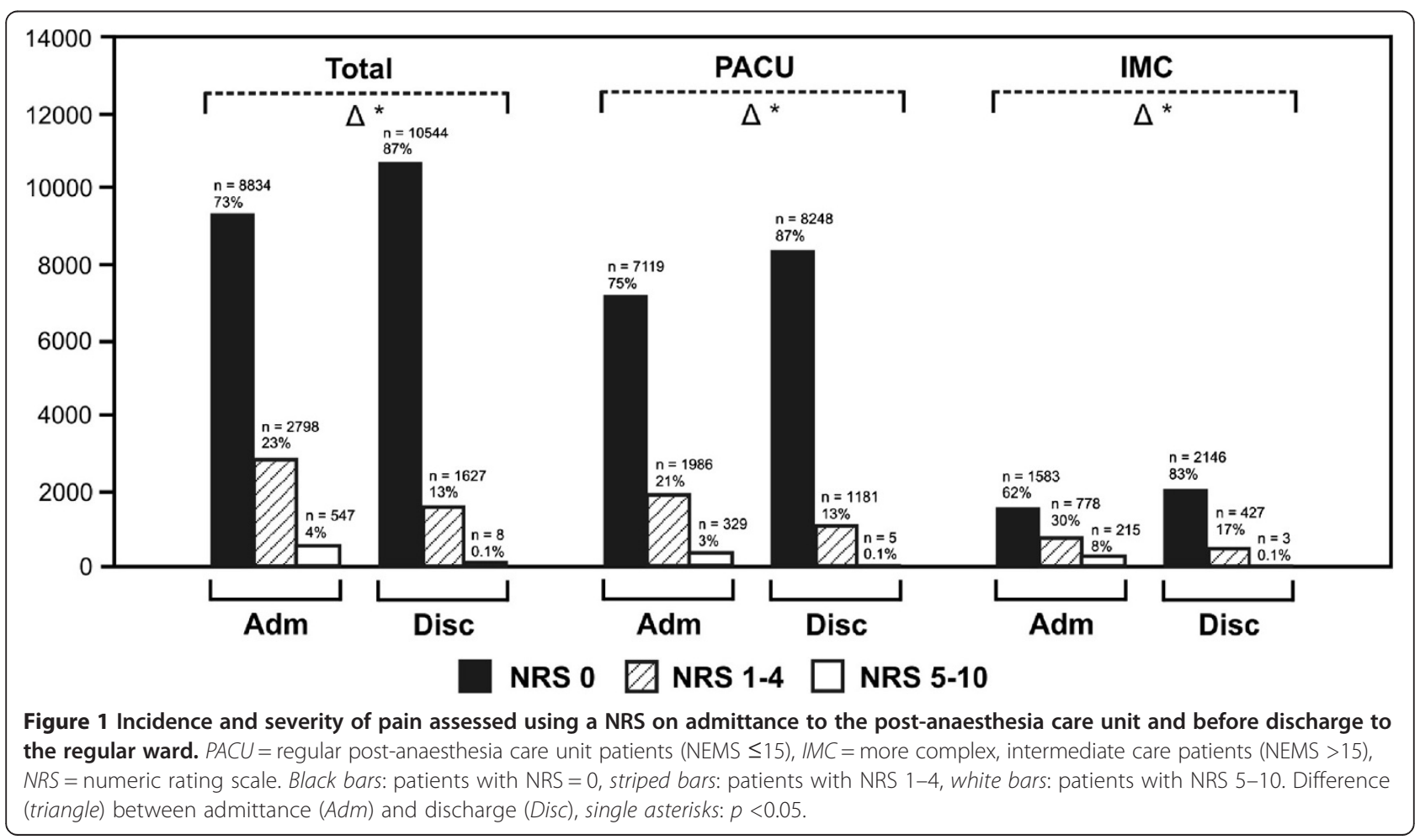


drugs (NSAID's), metamizol or a combination thereof. Next, when NRS pain intensity was greater than four, intravenous opioids (morphine, fentanyl or meperidine) were added. For major abdominal, thoracic and orthopaedic surgery, combined anaesthesia was performed and continued throughout the postoperative period whenever feasible. If there were contraindications for regional anaesthesia techniques, IV patient-controlled analgesia (PCA) pumps with opioids were initiated in the PACU and continued postoperatively.

Preoperatively, a systematic risk assessment for PONV was done for all patients. Regional anaesthesia was favoured for patients at risk for PONV whenever possible. For patient-related risk factors, we used the Apfel simplified risk score [10]. Together with procedure-related risk factors (e.g. type and duration of surgery, postoperative opioids), anaesthesia was planned together with a multimodal approach to minimize PONV [11]. For example, all patients with a risk score of two received total intravenous anaesthesia combined with a 5-HT3 antagonist (IV granisetron). For higher risk (i.e. Apfel score $\geq 3$ ), additional IV dexamethasone was given. For PONV treatment in the PACU, gradual therapy was administered using metoclopramid, granisetron, dexamethasone and droperidol [3]. In case of persistent, massive nausea and protracted vomiting, low dose propofol was given [12].

\section{Statistics}

Data were analyzed using SPSS for Windows, Release 12.0.0 (SPSS Inc., Chicago, IL) and Statview 5.01 Software (SAS Institute Inc., Cary, USA). Statistical analysis was

Table 2 Incidence of postoperative pain

\begin{tabular}{|c|c|c|c|c|c|c|c|}
\hline & & \multicolumn{3}{|c|}{ Pain on admittance, $n(\%)$} & \multicolumn{3}{|c|}{ Pain before discharge, $n(\%)$} \\
\hline & & NRS 0 & NRS 1-4 & NRS 5-10 & NRS 0 & NRS 1-4 & NRS 5-10 \\
\hline \multirow[t]{2}{*}{ Gender } & Women & 4,085 (69) & $1,528(26)$ & $279(5)$ & $5,029(85)$ & 857 (15) & $6(0)^{*}$ \\
\hline & Men & $4,775(76)$ & $1,268(20)$ & $270(4)^{* *}$ & $5,539(88)$ & 770 (12) & $4(0)^{*, * *}$ \\
\hline \multirow[t]{3}{*}{ Age } & $<40$ years & $801(61)$ & $416(32)$ & $95(7)$ & $1,030(78)$ & $281(21)$ & $1(1)^{*}$ \\
\hline & $40-80$ years & $5,789(72)$ & $1,850(23)$ & $370(5)^{* *}$ & 6,915 (86) & $1,087(14)$ & $7(0)^{*}$ \\
\hline & $>80$ years & $2,244(78)$ & $530(19)$ & $84(3)^{* *}$ & $2,597(91)$ & $259(9)$ & $2(0)^{* * * *}$ \\
\hline \multirow[t]{4}{*}{ ASA classification } & ASA I & $1,370(69)$ & $510(26)$ & $98(5)$ & $1,644(83)$ & $332(17)$ & $2(0)^{*}$ \\
\hline & ASA $\|$ & $4,008(73)$ & $1,246(23)$ & $253(4)^{* *}$ & $4,763(86)$ & $768(14)$ & $3(0)^{* * * *}$ \\
\hline & ASA III & $3,375(74)$ & $1,009(22)$ & $194(4)^{* *}$ & 4,066 (89) & $508(11)$ & $4(0)^{*, * *}$ \\
\hline & ASA IV & $81(70)$ & $31(27)$ & $4(3)$ & $96(83)$ & $19(16)$ & $1(1)^{*}$ \\
\hline \multirow[t]{7}{*}{ Surgical specialities } & General surgery & $4,872(67)$ & $1,961(27)$ & $404(6)$ & $6,081(84)$ & $1,151(16)$ & $5(0)^{*}$ \\
\hline & Cardiac surgery & $561(84)$ & $96(14)$ & $10(2)$ & $620(93)$ & $47(7)$ & $0(0)^{*, * *}$ \\
\hline & Orthopaedic surgery & 433 (64) & $194(29)$ & $48(7)^{* *}$ & $548(81)$ & 127 (19) & $0(0)^{* * * *}$ \\
\hline & Spine surgery & $403(67)$ & $155(26)$ & $45(7)$ & $499(83)$ & $102(17)$ & $2(0)^{*}$ \\
\hline & Urology & $1,357(86)$ & $198(12)$ & $29(2)^{* *}$ & $1,496(94)$ & $88(6)$ & $3(0)^{* * * *}$ \\
\hline & Ophthalmology & $1,102(87)$ & $160(13)$ & $5(0)^{* *}$ & $1,188(94)$ & $79(6)$ & $0(0)^{* * * *}$ \\
\hline & ENT surgery & $120(82)$ & $25(17)$ & $1(1)^{* *}$ & $131(90)$ & $15(10)$ & $0(0)^{* * * *}$ \\
\hline \multirow[t]{5}{*}{ Anaesthetic technique } & MAC & 391 (89) & $42(10)$ & $3(1)^{* *}$ & $404(93)$ & $32(7)$ & $0(0)^{*, * *}$ \\
\hline & Peripheral RA & $64(84)$ & $12(16)$ & $0(0)^{* *}$ & $71(93)$ & $5(7)$ & $0(0)^{*}$ \\
\hline & Central neuraxial RA & $973(92)$ & $62(7)$ & $13(1)^{* *}$ & $966(92)$ & $82(8)$ & $0(0)^{* * * *}$ \\
\hline & General anaesthesia & $6,220(69)$ & $2,303(26)$ & $456(5)$ & $7,692(85)$ & $1,280(15)$ & $7(0)$ \\
\hline & Combined anaesthesia & $1,187(73)$ & $377(23)$ & $68(4)$ & $1,411(86)$ & $228(14)$ & $1(0)^{*}$ \\
\hline \multirow[t]{3}{*}{ Duration of anaesthesia } & $<60 \min$ & $162(83)$ & $30(15)$ & $4(2)$ & $176(90)$ & $20(10)$ & $0(0)^{*}$ \\
\hline & $60-180 \min$ & $6,042(77)$ & $1,610(20)$ & $236(3)$ & $6,973(88)$ & 909 (12) & $6(0)^{*}$ \\
\hline & $>180 \min$ & $2,630(64)$ & $1,156(28)$ & $309(8)^{* *}$ & $3,393(83)$ & $698(17)$ & $4(0)^{*, * *}$ \\
\hline \multirow[t]{2}{*}{ Intensity of nursing care } & PACU & $7,288(66)$ & $1,986(21)$ & $329(5)$ & 8,417 (88) & $1,181(12)$ & $5(0)^{*}$ \\
\hline & IMC & $1,583(62)$ & 778 (30) & $215(8)^{* *}$ & $2,146(83)$ & $427(17)$ & $3(0)^{* * * *}$ \\
\hline
\end{tabular}

ASA classification American Society of Anesthesiologists' classification, ENT ear-nose-throat, IMC intermediate care (more complex, intermediate care patients, NEMS >15), MAC monitored anaesthesia care, NRS numeric rating scale, PACU post-anaesthesia care unit (regular post-anaesthesia care unit patients, NEMS $\leq 15$ ), $R A$ regional anaesthesia.

${ }^{*} \mathrm{p}<0.05$ (comparison admittance-discharge), ${ }^{* *} p<0.05$ (gender: comparison with women; age: comparison with age <40 years; ASA classification: comparison with ASA I; surgical specialities: comparison with general surgery; anaesthetic technique: comparison with general anaesthesia; duration of anaesthesia: comparison with duration <60 min; intensity of nursing: comparison with PACU). 
performed for the total patient collective and the following subgroups: gender, age, ASA classification, surgical specialities, anaesthetic technique, duration of anaesthesia and intensity of nursing care. $x^{2}$-test was used to compare pain intensity and incidence of PONV on admittance to the PACU and before discharge as well as to compare subgroups. To calculate predictors for length of PACU stay and postoperative pain, a linear multiple regression analysis (displaying $ß$-weight and significance levels) was used. Additionally, logistic regression analysis (displaying odds ratio and 95\% confidence intervals) was done to calculate predictors for postoperative nausea and vomiting. Data are given as mean value \pm standard deviation (SD). A $p$ value $<0.05$ was considered statistically significant.

\section{Results}

A total of 16,309 patients were cared for in the PACU during a time period of 30 months. This collective represents $41 \%$ of all patients that underwent anaesthesia in this time period. The data of 12,179 patients were available for statistical analysis. Sets of data $(4,130)$ had to be excluded because our questions related to pain and PONV could not be answered reliably. These patients had language difficulties or suffered from concomitant neurologic/ psychiatric diseases. Patient characteristics and case related data are presented in Table 1.

On admittance to the PACU, 73\% of patients were free of pain (NRS 0), 23\% of patients had minor pain (NRS $1-4)$ and $4 \%$ of patients suffered from severe pain (NRS $5-10$ ). Before discharge, $87 \%$ of patients were pain free, $13 \%$ of patients had minor pain and only $0.1 \%$ patients suffered from major pain. There was a significant difference in the presence of pain (NRS 1-10) on admission between regular PACU (24\%) and more complex IMC (38\%) patients (Figure 1). Incidence of postoperative pain for different subgroups is presented in Table 2. Risk factors for increased postoperative pain (on admittance) determined by multivariate analysis were female gender; higher ASA classification; general, cardiac and orthopaedic surgery and prolonged case duration. Furthermore, the performance of general anaesthesia without the combination of regional anaesthesia was an independent risk factor. By contrast, old age, ophthalmologic procedures or ENT surgery were predictive for lower pain scores (Table 3).

PONV was observed in 257 patients on admittance to the PACU, whereas 21 patients were vomiting. Until discharge

Table 3 Multivariate analysis

\begin{tabular}{|c|c|c|c|c|c|c|}
\hline \multirow[b]{2}{*}{ Independent variables } & \multirow{2}{*}{$\begin{array}{l}\text { Length of stay } \\
\beta\end{array}$} & \multirow{2}{*}{$\begin{array}{l}\text { Postoperative pain } \\
\text { B }\end{array}$} & \multicolumn{2}{|c|}{ Postoperative nausea } & \multicolumn{2}{|c|}{ Postoperative vomiting } \\
\hline & & & OR & $95 \% \mathrm{Cl}$ & OR & $95 \% \mathrm{Cl}$ \\
\hline Gender & 0.008 & $0.055^{* *}$ & $2.455^{* *}$ & $1.783 / 3.382$ & $3.194^{* *}$ & $1.755 / 5.816$ \\
\hline Age & $0.036^{* *}$ & $-0.148^{* *}$ & $0.988^{*}$ & 0.979/0.998 & 0.992 & $0.974 / 1.009$ \\
\hline ASA classification & $0.159^{* *}$ & $0.062^{* *}$ & 1.101 & $0.859 / 1.410$ & 0.915 & $0.593 / 1.414$ \\
\hline \multicolumn{7}{|l|}{ Surgical specialities } \\
\hline General surgery & -0.047 & $0.074^{*}$ & 0.511 & $0.232 / 1.126$ & 0.584 & $0.138 / 2.467$ \\
\hline Cardiac surgery & $0.058^{* *}$ & $0.062^{* *}$ & 0.411 & $0.128 / 1.325$ & 0.781 & $0.091 / 6.678$ \\
\hline Orthopaedic surgery & -0.021 & $0.099^{* *}$ & 0.583 & $0.223 / 1.525$ & 0.853 & $0.162 / 4.484$ \\
\hline Spine surgery & $0.058^{* *}$ & 0.014 & 0.450 & $0.168 / 1.206$ & 0.716 & $0.133 / 3.853$ \\
\hline Urology & $-0.073^{* *}$ & -0.015 & 0.015 & $0.979 / 0.998$ & 0.530 & $0.093 / 3.036$ \\
\hline Ophthalmology & $-0.126^{* *}$ & $-0.073^{* *}$ & $0.299^{*}$ & $0.107 / 0.834$ & 0.250 & $0.034 / 1.856$ \\
\hline ENT surgery & $-0.071^{* *}$ & $-0.036^{* *}$ & 0.689 & $0.170 / 2.792$ & n.a. & n.a. \\
\hline \multicolumn{7}{|l|}{ Anaesthetic technique } \\
\hline MAC & $-0.055^{* *}$ & $0.028^{*}$ & $3.825^{*}$ & $1.172 / 12.485$ & 0.813 & $0.090 / 7.330$ \\
\hline RA & -0.001 & $-0.046^{* *}$ & $2.675^{*}$ & $1.047 / 6.830$ & 0.422 & $0.049 / 3.653$ \\
\hline General anaesthesia & $0.041^{* *}$ & $0.104^{* *}$ & 1.365 & $0.708 / 2.633$ & 0.607 & $0.251 / 1.468$ \\
\hline Combined anaesthesia & $0.031^{*}$ & 0.010 & 1.101 & $0.514 / 2.359$ & 0.647 & $0.226 / 1.851$ \\
\hline Duration of anaesthesia & $0.432^{* *}$ & $0.144^{* *}$ & $1.003^{* *}$ & $1.001 / 1.005$ & 1.003 & $1.000 / 1.006$ \\
\hline Postoperative pain & $0.051^{* *}$ & n.a. & $1.161^{* *}$ & $1.084 / 1.244$ & $1.224^{*}$ & $1.099 / 1.363$ \\
\hline Postoperative nausea/vomiting & $0.025^{* *}$ & n.a. & n.a. & n.a. & n.a. & n.a. \\
\hline
\end{tabular}


to the ward, 224 of these 257 patients were free of symptoms and 103 patients $(0.8 \%)$ developed new nausea (data not shown). Therefore at the time of discharge, a total of 135 patients had nausea but none suffered from vomiting (Figure 2). A total of 360 patients (3\%) had PONV during the recovery period. Subgroup analysis showed a significant reduction of postoperative nausea and vomiting during the PACU stay for all patient groups except for those undergoing spine surgery and patients with higher ASA classification (Table 4). Patients with major pain levels (NRS 5-10) on admittance had a higher incidence of postoperative nausea $(5.3 \%)$ and vomiting $(1.3 \%)$ compared to patients with lower pain levels (NRS $0-4$; nausea $2.2 \%$, vomiting $0.2 \%, p<0.05)$. Risk factors for nausea in the multiple linear regression analysis were female gender, monitored anaesthesia care and performance of regional anaesthesia. By contrast, reduced nausea occurred in older patients and a patient undergoing ophthalmologic procedures. The only independent risk factors for postoperative vomiting were female gender and postoperative pain (Table 3).

Duration of PACU stay was longer in a woman compared to a man and PACU stay became longer with increasing age, ASA classification and anaesthesia time (Table 1). Levels of pain and presence of PONV on admittance correlated with the length of stay: for example, patients with no pain or no PONV stayed for $5.3 \pm 5.5$ or $5.7 \pm 5.9 \mathrm{~h}$, whereas patients with severe pain (NRS 5-10) or nausea/ vomiting stayed significantly longer $(9.0 \pm 7.3$ or $7.4 \pm 7.5$ / $10.0 \pm 8.9 \mathrm{~h}$; Figure 3 ). Risk factors for prolonged stay, as determined by multiple regression analysis, are shown in Table 3.

\section{Discussion}

In the present PACU quality audit, the majority of the studied 12,179 patients had good pain control (73\% and $87 \%$ of patients were pain free on arrival and on discharge to the ward, respectively) and the incidence of PONV was $3 \%$ overall. In more complex IMC patients, pain scores were higher on arrival but dropped to similar levels on discharge compared to regular PACU patients. The levels of pain and presence of PONV on arrival correlated with the length of stay in the PACU. Thereby, pain- or PONVfree patients stayed almost half of the time in the PACU compared to patients with severe pain or vomiting on arrival.

The incidence of early postoperative pain in our study (Figure 1, Table 2) is only half or even less of commonly cited postoperative pain levels in the literature [13-15].

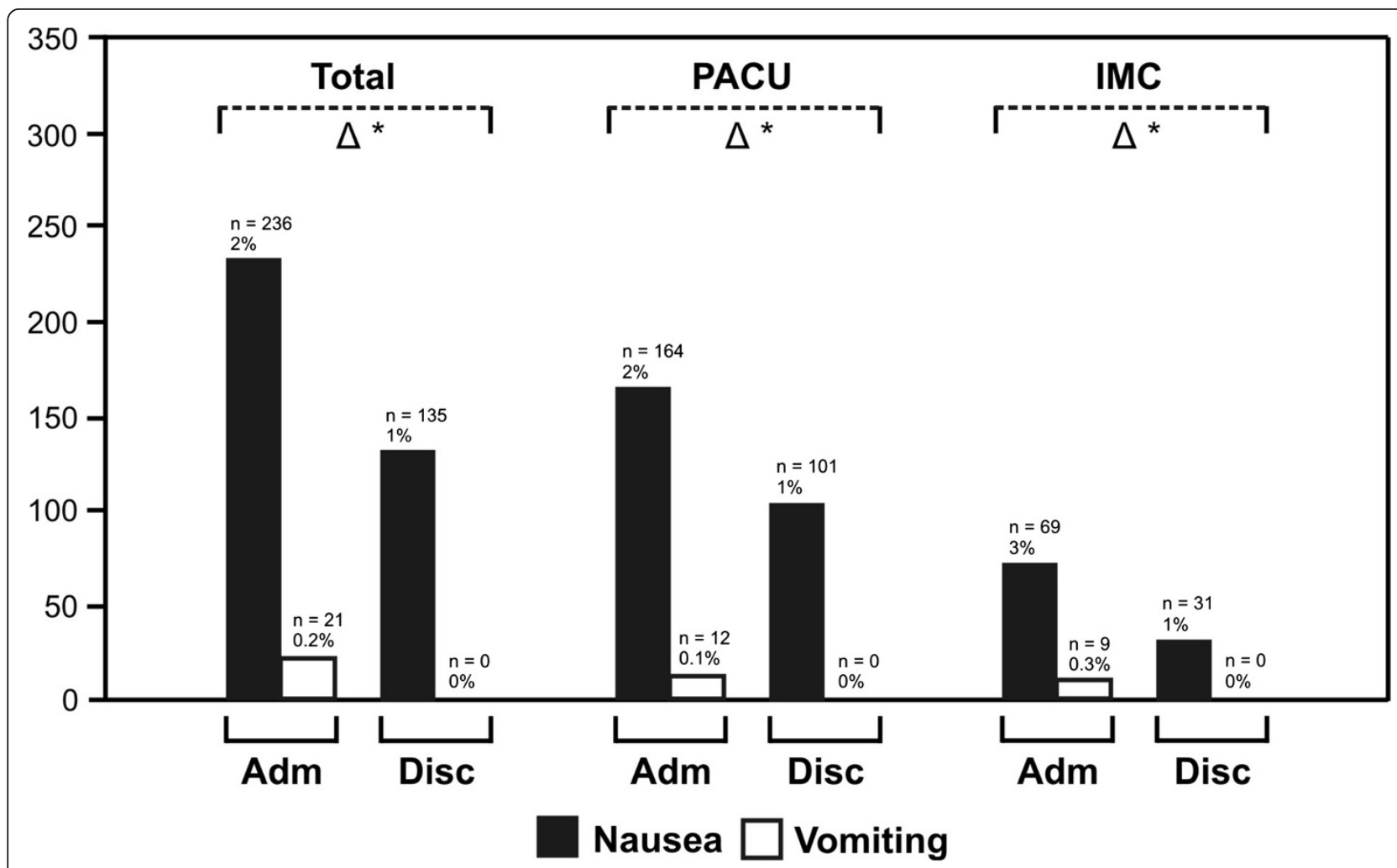

Figure 2 Incidence of postoperative nausea and vomiting on admittance to the post-anaesthesia care unit and before discharge to the regular ward. $P A C U=$ regular post-anaesthesia care unit patients (NEMS $\leq 15), I M C=$ more complex, intermediate care patients (NEMS $>15)$. Black bars: patients with postoperative nausea, white bars: patients with postoperative vomiting. Difference (triangle) between admittance (Adm) and discharge (Disc), single asterisks: $p<0.05$. 
Several reasons may explain this difference: our patients were asked about their postoperative pain during their PACU stay with a simple numeric rating scale only, whereas the other studies performed more complex telephone or written surveys several weeks and months after the surgical procedures and asked for global postoperative pain experience. The results are therefore not comparable since two different things were measured.

Prompt and appropriate management of pain initiated in a PACU environment and continued on a regular ward may have a positive impact on patient satisfaction and perception of pain according to results of studies on the implementation of PACU-based pain services $[16,17]$. Our data are in accordance with these recommendations and show that pain relief was effective in our PACU resulting in a significant reduction of postoperative pain from admittance to discharge (Figure 1). Multivariate analysis revealed a variety of risk factors for increased postoperative pain (Table 3). Our data agree with previously published large trials, where younger age and type of surgery (e.g. major general, orthopaedic and cardiac surgery under general anaesthesia) were predictors for postoperative pain $[13,18,19]$. Concerning female gender as a predictor for increased postoperative pain, studies report conflicting results, however [19]. Patients at risk for increased postoperative pain may have a clear benefit from postoperative care in a PACU. On the other hand, patients undergoing surgery under regional anaesthesia may initially present in a pain free state. Nevertheless, PACU pain management can still be appropriate for these patients, e.g.

Table 4 Incidence of postoperative nausea and vomiting (PONV)

\begin{tabular}{|c|c|c|c|c|c|}
\hline & & \multicolumn{2}{|l|}{ Nausea, $n(\%)$} & \multicolumn{2}{|l|}{ Vomiting, $n$ (\%) } \\
\hline & & On admittance & Before discharge & On admittance & Before discharge \\
\hline \multirow[t]{2}{*}{ Gender } & Women & $163(3)$ & $103(2)^{*}$ & $15(0.3)$ & $0(0)^{*}$ \\
\hline & Men & $73(1)^{* *}$ & $32(1)^{*}$ & $6(0.2)$ & $0(0)^{*}$ \\
\hline \multirow[t]{3}{*}{ Age } & $<40$ years & $38(3)$ & $17(1)^{*}$ & $4(0.4)$ & $0(0)^{*}$ \\
\hline & $40-80$ years & $134(2)^{* *}$ & $87(1)^{*}$ & $16(0.4)$ & $0(0)^{*}$ \\
\hline & $>80$ years & $64(2)^{* *}$ & $(1)^{*}$ & $1(0)$ & $0(0)$ \\
\hline \multirow[t]{4}{*}{ ASA classification } & ASA I & $33(2)$ & $21(1)^{*}$ & $2(0)$ & $0(0)$ \\
\hline & ASA $\|$ & $115(2)$ & $65(1)^{*}$ & $15(1) * *$ & $0(0)^{*}$ \\
\hline & ASA III & $88(2)$ & $48(1)^{*}$ & $4(0)$ & $0(0)$ \\
\hline & ASA IV & $0(0)$ & $1(1)^{*}$ & $0(0)^{* *}$ & $0(0)$ \\
\hline \multirow[t]{7}{*}{ Surgical specialities } & General surgery & $146(2)$ & $88(1)^{*}$ & $13(0)$ & $0(0)^{*}$ \\
\hline & Cardiac surgery & $12(3)$ & $3(1)^{*}$ & $0(0)$ & $0(0)$ \\
\hline & Orthopaedic surgery & $18(3)$ & $5(1)^{*}$ & $2(1)$ & $0(0)^{*}$ \\
\hline & Spine surgery & $12(2)$ & $17(3)$ & $5(1)$ & $0(0)^{*}$ \\
\hline & Urology & $24(1)^{* *}$ & $15(1)^{*}$ & $0(0)$ & $0(0)$ \\
\hline & Ophthalmology & $11(1)^{* *}$ & $5(0)^{*}$ & $0(0)$ & $0(0)$ \\
\hline & ENT surgery & $3(2)$ & $0(0)^{*}$ & $0(0)$ & $0(0)$ \\
\hline \multirow[t]{5}{*}{ Anaesthetic technique } & MAC & $12(3)$ & $6(1)^{*}$ & $0(0)$ & $0(0)$ \\
\hline & Peripheral RA & $1(1)$ & $0(0)^{*}$ & $0(0)$ & $0(0)$ \\
\hline & Central neuraxial RA & $12(2)$ & $6(1)^{*}$ & $1(0)$ & $0(0)$ \\
\hline & General anaesthesia & $178(2)$ & $104(1)^{*}$ & $19(0)$ & $0(0)^{*}$ \\
\hline & Combined anaesthesia & $33(2)$ & $19(1)^{*}$ & $1(0)$ & $0(0)$ \\
\hline \multirow[t]{3}{*}{ Duration of anaesthesia } & $<60 \min$ & $6(3)$ & $3(2)^{*}$ & $1(1)$ & $0(0)$ \\
\hline & $60-180 \mathrm{~min}$ & $120(4)$ & $77(1)^{*}$ & $7(0)$ & $0(0)$ \\
\hline & $>180 \mathrm{~min}$ & $110(3)$ & $55(1)^{*}$ & $13(0)$ & $0(0)^{*}$ \\
\hline \multirow[t]{2}{*}{ Intensity of nursing care } & PACU & $164(2)$ & $101(1)^{*}$ & $12(0.1)$ & $0(0)^{*}$ \\
\hline & IMC & $69(3)^{* *}$ & $31(1)^{*}$ & $9(0.3)$ & $0(0)^{*}$ \\
\hline
\end{tabular}

ASA classification American Society of Anesthesiologists' classification, ENT ear-nose-throat, IMC intermediate care (more complex intermediate care patients, NEMS >15), MAC monitored anaesthesia care, NRS numeric rating scale, PACU post-anaesthesia care unit (regular post-anaesthesia care unit patients NEMS $\leq 15$ ), $R A=$ regional anaesthesia.

${ }^{*} p<0.05$ (comparison admittance-discharge), ${ }^{* *} p<0.05$ (gender: comparison with women; age: comparison with age <40 years; ASA classification: comparison with ASA I; surgical specialities: comparison with general surgery; anaesthetic technique: comparison with general anaesthesia; duration of anaesthesia: comparison with duration <60 min; intensity of nursing: comparison with PACU). 


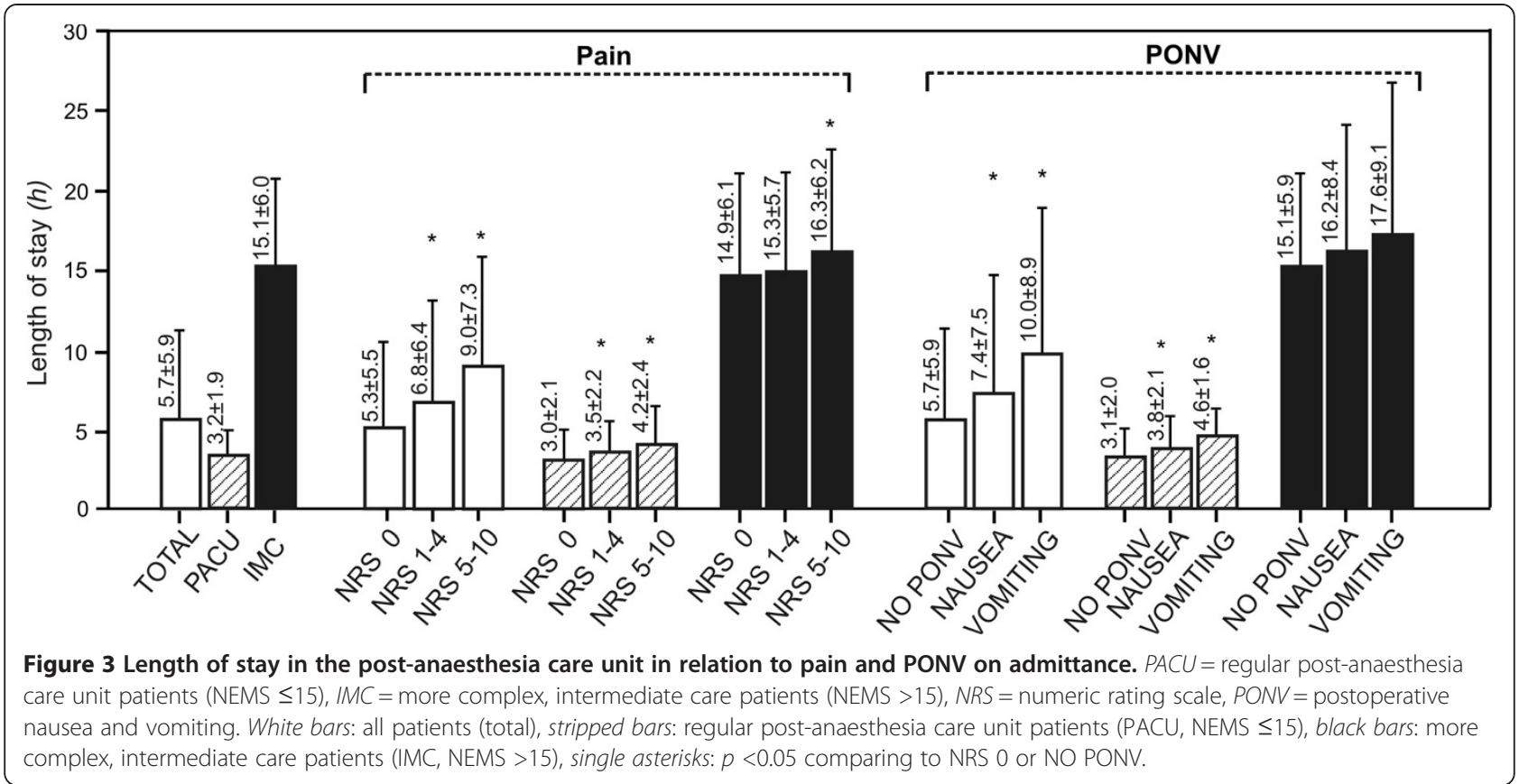

to adjust continuous regional anaesthesia or to initiate and titrate systemic intravenous analgesia.

The incidence of PONV revealed in this study was much lower than the $25 \%-30 \%$ found in the literature (Figure 2, Table 4) [11]. This might be explained by the fact that preoperatively a systematic risk assessment was done for PONV in all patients and regional anaesthesia favoured whenever possible. According to the present study, the care in our PACU was able to significantly reduce postoperative nausea. A reduction of approximately $50 \%$ was observed in the total patient population as well as in the majority of the subgroups. Postoperative nausea was completely controlled during the PACU stay for all patients. The fact that women are especially prone to PONV has been demonstrated repeatedly [10] and is again supported by our data. Female patients obviously benefit from a post-anaesthesia care service.

An increased incidence of PONV was observed in patients with higher pain scores on PACU admittance. This finding may be explained by a higher use of opioids in order to control postoperative pain. Only recently, a study evaluating the relationship between postoperative opioid administration and PONV has been published and a logarithmic dose-effect relationship could be established [20]. In the present study, we did not record the individual doses and dosing intervals of opioids. However, we could show that postoperative pain is an independent predictor for PONV (Table 3). Based on these findings, profound intraoperative and early postoperative analgesia should be promoted to minimise deliberate use of postoperative opioids. This goal may be achieved by an increased use of multimodal analgesia techniques, including regional anaesthesia or combined anaesthetic techniques [21,22].

A limitation of the present investigation is the heterogeneity of the studied patient population with regard to the surgical specialities and the intraoperative anaesthetic technique. On the other side, by representing daily clinical reality, this heterogeneity could also be interpreted as strength. Additionally, our pain scores were not compared to preoperative values and both pain and PONV were just measured in the PACU period. To get more detailed information and to increase validity, it would be interesting for future studies to compare pain levels to baseline levels before and to add a follow-up on pain and PONV experience several weeks after their PACU stay.

\section{Conclusions}

We conclude that the majority of PACU patients had good pain control, both on admittance and before discharge and that the overall incidence of PONV was low. Managing patients in the PACU could achieve a significant reduction of pain and PONV. The level of pain and presence of PONV on admittance to the PACU correlate with and act as predictors for increased length of PACU stay.

\section{Abbreviations}

IMC: intermediate care; NEMS: nine equivalents of nursing manpower use score; NRS: numeric rating scale; OR: operating room; PACU: post-anaesthesia care unit; PCA: patient-controlled analgesia; PONV: postoperative nausea and vomiting.

\section{Competing interests}

The authors declare that they have no competing interests. 


\section{Authors' contributions}

MTG contributed to study design, data collection, data analysis and manuscript preparation. SD, SB and SB contributed to conduct of the study, data collection and manuscript preparation. TH contributed to data collection and data analysis. RK contributed to study design, data analysis and manuscript preparation. AZ and $\mathrm{CKH}$ contributed to study design, conduct of the study, data collection, data analysis and manuscript preparation. All authors read and approved the final manuscript.

\section{Acknowledgements}

The authors would like to thank Alfred Jaros for his help in data management. This study has been funded through institutional support only.

\section{Author details}

${ }^{1}$ Institute of Anaesthesiology and Pain Medicine, Kantonsspital Winterthur, Brauerstrasse 15, 8401 Winterthur, Switzerland. 'Institute of Anaesthesiology and Intensive Care Medicine, Triemli City Hospital Zurich,

Birmensdorferstrasse 497, 8063 Zurich, Switzerland. ${ }^{3}$ Department of Psychiatry and Psychotherapy, Statistics, University Hospital Zurich, Raemistrasse 100, 8006 Zurich, Switzerland.

Received: 17 April 2014 Accepted: 4 November 2014

Published online: 26 November 2014

\section{References}

1. Eichenberger AS, Haller G, Cheseaux N, Lechappe V, Garnerin P, Walder B: A clinical pathway in a post-anaesthesia care unit to reduce length of stay, mortality and unplanned intensive care unit admission. Eur J Anaesthesiol 2011, 28:859-866.

2. Vimlati L, Gilsanz F, Goldik Z: Quality and safety guidelines of postanaesthesia care: working party on post anaesthesia care (approved by the European board and section of anaesthesiology, Union Européenne des Médecins Spécialistes). Eur J Anaesthesiol 2009, 26:715-721.

3. Apfelbaum $J$, Silverstein $J H_{1}$, Chung FF, Connis RT, Fillmore RB, Hunt SE, Nickinovich DG, Schreiner MS: Practice guidelines for postanesthetic care: an updated report by the American Society of anesthesiologists task force on postanesthetic care. Anesthesiology 2013, 118:291-307.

4. Gornall BF, Myles PS, Smith CL, Burke JA, Leslie K, Pereira MJ, Bost JE, Kluivers KB, Nilsson UG, Tanaka Y, Forbes A: Measurement of quality of recovery using the QoR-40: a quantitative systematic review. $\mathrm{Br} J$ Anaesth 2013, 111:161-169.

5. Lalani SB, Ali F, Kanji Z: Prolonged-stay patients in the PACU: a review of the literature. J Perianesth Nurs 2013, 28:151-155.

6. Reis Miranda D, Moreno R, lapichino G: Nine equivalents of nursing manpower use score (NEMS). Intensive Care Med 1997, 23:760-765.

7. Breivik H, Borchgrevink PC, Allen SM, Rosseland LA, Romundstad L, Hals EK, Kvarstein G, Stubhaug A: Assessment of pain. Br J Anaesth 2008, 101:17-24.

8. Gandhi K, Baratta JL, Heitz JW, Schwenk ES, Vaghari B, Viscusi ER: Acute pain management in the postanesthesia care unit. Anesthesiol Clin 2012, 30:e1-e15.

9. American Society of Anesthesiologists Task Force on Acute Pain M: Practice guidelines for acute pain management in the perioperative setting: an updated report by the American Society of Anesthesiologists Task Force on Acute Pain Management. Anesthesiology 2012, 116:248-273.

10. Apfel CC, Laara E, Koivuranta M, Greim CA, Roewer N: A simplified risk score for predicting postoperative nausea and vomiting: conclusions from cross-validations between two centers. Anesthesiology 1999, 91:693-700.

11. Gan TJ, Diemunsch P, Habib AS, Kovac A, Kranke P, Meyer TA, Watcha M, Chung F, Angus S, Apfel CC, Bergese SD, Candiotti KA, Chan MT, Davis PJ, Hooper VD, Lagoo-Deenadayalan S, Myles P, Nezat G, Philip BK, Tramèr MR: Consensus guidelines for the management of postoperative nausea and vomiting. Anesth Analg 2014, 118:85-113.

12. Unlugenc $H$, Guler $T$, Gunes $Y$, Isik G: Comparative study of the antiemetic efficacy of ondansetron, propofol and midazolam in the early postoperative period. Eur J Anaesthesiol 2004, 21:60-65.

13. Apfelbaum JL, Chen C, Mehta SS, Gan TJ: Postoperative pain experience: results from a national survey suggest postoperative pain continues to be undermanaged. Anesth Analg 2003, 97:534-540. table of contents.

14. Rocchi A, Chung F, Forte L: Canadian survey of postsurgical pain and pain medication experiences. Can J Anaesth 2002, 49:1053-1056.
15. Gan TJ, Habib AS, Miller TE, White W, Apfelbaum JL: Incidence, patient satisfaction, and perceptions of post-surgical pain: results from a US national survey. Curr Med Res Opin 2014, 30:149-160.

16. Leykin Y, Pellis T, Ambrosio C, Zanette G, Malisano A, Rapotec A, Casati A: A recovery room-based acute pain service. Minerva Anestesiol 2007 73:201-206.

17. Rawal N: Organization, function, and implementation of acute pain service. Anesthesiol Clin North America 2005, 23:211-225.

18. Kalkman CJ, Visser K, Moen J, Bonsel GJ, Grobbee DE, Moons KG: Preoperative prediction of severe postoperative pain. Pain 2003, 105:415-423

19. Ip HY, Abrishami A, Peng PW, Wong J, Chung F: Predictors of postoperative pain and analgesic consumption: a qualitative systematic review. Anesthesiology 2009, 111:657-677.

20. Roberts GW, Bekker TB, Carlsen HH, Moffatt CH, Slattery PJ, McClure AF: Postoperative nausea and vomiting are strongly influenced by postoperative opioid use in a dose-related manner. Anesth Analg 2005 101:1343-1348.

21. Brennan F, Carr DB, Cousins M: Pain management: a fundamental human right. Anesth Analg 2007, 105:205-221.

22. Prabhakar A, Mancuso KF, Owen CP, Lissauer J, Merritt CK, Urman RD, Kaye AD: Perioperative analgesia outcomes and strategies. Best Pract Res Clin Anaesthesiol 2014, 28:105-115.

doi:10.1186/s13741-014-0010-8

Cite this article as: Ganter et al:: The length of stay in the post-anaesthesia care unit correlates with pain intensity, nausea and vomiting on arrival. Perioperative Medicine 2014 3:10.

\section{Submit your next manuscript to BioMed Central and take full advantage of:}

- Convenient online submission

- Thorough peer review

- No space constraints or color figure charges

- Immediate publication on acceptance

- Inclusion in PubMed, CAS, Scopus and Google Scholar

- Research which is freely available for redistribution

Submit your manuscript at www.biomedcentral.com/submit
C Biomed Central 